\title{
EDITORIAL
}

\section{Joint statement on dual disorders: Addiction and other mental disorders}

\author{
Néstor Szerman, ${ }^{1,2,4}$ José Martínez-Raga, ${ }^{1,2,4}$ Rubén Baler, ${ }^{3}$ Carlos Roncero, ${ }^{1,2,4}$ Pablo Vega, ${ }^{1,4}$ Ignacio Basurte, ${ }^{1,2,4}$ \\ Lara Grau-López, ${ }^{1,2,4}$ Marta Torrens, ${ }^{1,2,4}$ Miguel Casas, ${ }^{1,2,4}$ Celia Franco, ${ }^{1,2}$ Giampaolo Spinnato, ${ }^{1}$ Icro Maremmani, ${ }^{1,2}$ \\ Angelo G.I. Maremmani, ${ }^{1}$ Jean-Pierre Daulouède, ${ }^{1}$ Arkaitz Aguerretxe-Colina, ${ }^{1}$ Karl Mann, ${ }^{1,5}$ \\ Rodrigo Marín-Navarrete, ,1,2,4,6 María Elena Medina-Mora, ${ }^{1,6}$ Pedro Ruiz ${ }^{1,2}$
}

\footnotetext{
1 World Association on Dual Disorders, Madrid, España.

2 World Psychiatry Association / Section on Dual Disorders, Geneva, Switzerland.

3 National Institute on Drug Abuse, Bethesda, United States.

4 Sociedad Española de Patología Dual, Madrid, Spain.

${ }^{5}$ European Federation on Addiction Societies, Mannheim, Germany.

6 Instituto Nacional de Psquiatría Ramón de la Fuente Muñiz, Ciudad de México, México.

Correspondence:

Néstor Szerman

Hospital Universitario Gregorio

Marañón

C/ Lope de Rueda 4328009 Madrid, España.

Phone: +34914008690

Fax: +34 915739932

Email: nszerman@salud.madrid.org

doi:10.17711/SM.0185-3325.2017.031
}

The World Association on Dual Disorders (WADD), the World Psychiatric Association (WPA) (Section on Dual Disorders), and the Sociedad Española de Patología Dual (SEPD) have joined forces to clarify that:

Addiction is a mental disorder, not a voluntary, self-indulgent act.

- Dual disorder is a term applied to people who have an addictive disorder and another co-occurring mental disorder. It is related to interacting neurobiological and environmental factors involved in behaviors of substance and non-substance related disorders. Nobody chooses to become an addict, and addiction is not a matter of weakness of will, a consequence of self-indulgent behavior, or a result of the mere pursuit of pleasure.

- The above mentioned national and international scientific associations have drawn up a statement supporting the notion that addictions are mental disorders in response to unfounded claims to this assertion.

- Patients with mental disorders, including addictions, should have access to a multidisciplinary care model that integrates and/or coordinates the mental health network and the addiction network, thereby avoiding the so-called "wrong door syndrome."

- The mental/brain disorder model of addictions has led to the development of effective preventive measures, treatment interventions, and public health policies. However, the concept of substance use disorders and dual disorders as brain diseases continues to be questioned, possibly because the neurobiological basis of these compulsive behaviors has not been fully explained.

Addictive behaviors are mental disorders, as evidenced by basic and clinical research in the neurosciences field. Neurobiological and environmental factors are involved in the behaviors underlying both substance (tobacco, cocaine, cannabis, alcohol abuse...) and non-substance related disorders (gambling, sex, food...). Although the recognition of addiction as a mental/brain disorder has led to effective preventive measures, treatment approaches, and public health policies according to the WADD, the WPA (Section on Dual Disorders), and the SEPD, this conceptualization is still being questioned by certain opinion groups.

As explained by Dr. Nora Volkow, Director of the US National Institute on Drug Abuse (NIDA), "One of the reasons why the concept of addiction as a mental disorder continues to be questioned is perhaps the fact that neuroscientific research has only recently begun to shed light on the neurobiological mechanisms underlying these behaviors." In her opinion, "the concept of addiction as a mental illness or disease of the brain challenges deeply ingrained values about self-determination and personal responsibility that frame addictive drug use as a voluntary, hedonistic act" (Volkow, Koob, \& McLellan, 2016).

Recent publications, albeit without scientific evidences, question the advances in the field of neuroscience, considering addictive people as responsible of pursuing pleasurable 
Table 1

Institutions, organizations, and associations that have joined the statement

\begin{tabular}{lll}
\hline Institutions / Organizations / Associations & \multicolumn{1}{c}{ City, Country } & \multicolumn{1}{c}{ Website } \\
\hline National Institute on Drug Abuse & Maryland, USA & https://www.drugabuse.gov/ \\
Instituto Nacional de Psiquiatría Ramón de la Fuente Muñiz & Mexico City, Mexico & http://www.inprf.gob.mx/ \\
World Association on Dual Disorders & Madrid, Spain & http://www.worlddualdisorders.org/ \\
World Psychiatry Association (Section on Dual Disorders) & Geneva, Switzerland & http://www.wpanet.org/ \\
European Federation on Addiction Societies & Mannheim, Germany & http://www.eufas.net \\
Sociedad Española de Patología Dual & Madrid, Spain & http://www.patologiadual.es/ \\
Asociación Colombiana de Patología Dual & Medellin, Colombia & http://www.patologiadual.co/ \\
Associação Portuguesa de Patologia Dual & Coimbra, Portugal & http://www.patologiadual.pt/ \\
Associação Brasileira de Impulsividade e Patologia Dual & Rio de Janeiro, Brasil & https://abipd.com.br \\
Centro de Investigación Biomédica en Red Salud Mental (CIBERSAM) / & Madrid, Spain & http://www.cibersam.es/ \\
Instituto Carlos III & Madrid, Spain & www.redrta.es \\
Red de Trastornos Adictivos / Instituto Carlos III & &
\end{tabular}

and ultimately self-indulgent behaviors. In this regard, the SEPD would like to clarify that "nobody chooses to become addicted." Whilst contact with drugs or substances with abuse potential is determined by social factors, vulnerability to addiction is determined by individual factors (National Institute on Drug Abuse, 2007). Remarkably, only a small proportion of individuals exposed to licit or illicit drugs develop compulsive drug-seeking behavior and the vast majority of them have a co-occurring mental disorder. As clarified by the WADD, the WPA (Section on Dual Disorders), and the SEPD, "Not everyone who uses drugs becomes addicted, and those that do become addicted do not choose to do so."

\section{Ten-point statement}

In view of the above the WADD, the WPA (Section on Dual Disorders) and the SEPD have joined forces to draw up the following 10-point statement.

1. According to the current international diagnostic classifications of the World Health Organization and the American Psychiatric Association (APA), the International Classification of Diseases and the Diagnostic and Statistical Manual of Mental Disorders, respectively (APA, 2013), addictions are mental disorders, and like any other mental disorder, they are not a problem of will power, character failure, or self-indulgence.

2. There is solid scientific evidence that supports the acknowledgement that addiction, like other mental disorders, is a brain disease, and this in turn has given rise to what is known as the brain disease model of addiction (Volkow et al., 2016).

3. As with other mental disorders, current diagnostic classification systems allow for a dimensional assessment of addictions: mild, moderate, and severe. Severe addiction can involve a stronger physiological component, relapse is common, and the condition can become chronic (American Psychiatric Association, 2013).
4. The most severe clinical characteristics of addiction will develop in approximately $10 \%$ of the individuals exposed to addictive drugs. They will develop a mental disorder termed substance use and/or addictive disorder. Their susceptibility or vulnerability is determined by the interaction of individual, genetic, psychopathological, and environmental factors (Volkow et al., 2016).

5. In the vast majority of cases, addictions co-occur with another mental disorder. This is a clinical condition identified or called dual disorder or co-occurring disorder (Szerman et al., 2013). According to data from large epidemiological studies, at least $70 \%$ of addicted individuals have dual disorders, although current evidence suggests that this figure has probably been underestimated (Arias et al., 2013). Likewise, over 50\% of people with a mental disorder have a lifetime addictive disorder (Lev-Ran, Imtiaz, Rehm, \& Le Foll, 2013). Current scientific evidence shows that addiction and a co-occurring mental disorder are not separate disorders, but rather different, interacting, clinical conditions. They may occur simultaneously or sequentially, and may develop due to individual and environmental factors (Leyton \& Vezina, 2014; Szerman \& Martinez-Raga, 2015).

6. Epidemiological studies have not analyzed behavioral addictions such as gambling disorders, which are now recognized as being equivalent to substance use disorders due to their clinical and neurobiological similarities. However, behavioral addictions, also occur in vulnerable people and in patients with co-occurring mental disorders (Kessler et al., 2008).

7. Patients with addictive or dual disorders may also have other medical conditions, such as infectious diseases, as an integral part of the dual disorder process (Roncero et al., 2016).

8. Substances with addictive potential have different, and sometimes opposite, effects on different groups of individuals, hence the importance of a personalized or precise medicine approach (Van Os, Delespaul, Wigman, Myin-Germeys, \& Wichers, 2013; Mann et al., 2017). 
The concept dual disorder allows for an integral personalized biopsychosocial approach in which treatment is tailored to the individual and not to the substance.

9. Patients with mental disorders, including addictions, require access to a multidisciplinary care model that integrates and/or coordinates a mental health network and addiction resources. The existence, as is often the case, of two separate treatment networks, one for addictions and another for mental disorders, for a single patient leads to what is known as the "wrong door syndrome." Any patient has the right to an adequate assessment by health care specialists and access to integrated, evidence-based treatments for dual disorders. The existence of two separate care networks is neither sufficiently effective nor sufficiently efficient, and, as shown by the Madrid epidemiological study, results in a failure to diagnose many patients with dual disorder, denying them access to integrated care (Greenfield \& Weiss, 2015; Minkoff, 2001).

10. The concept of dual disorders, based on neuroscience (Volkow, 2001), a strongly multidisciplinary field, is the only guarantee that patients with addiction disorders, just like those with other mental disorders, will be treated with an integrated approach that combines both biological factors and psychological and social support.

In the 1980 s, in many settings, people with mental disorders were integrated into the health care system, but this was not the case for patients with addiction disorders, who were excluded and assigned to discriminatory, differentiated networks. Accordingly, the above scientific societies would like to highlight the importance of "applying scientific knowledge from medicine, psychiatry, and psychology to the treatment of addictions and dual disorders. This treatment must be evidence-based, patient-centered, integrated, of a high quality, and freely available to all. This will help to avoid repeating past mistakes and at the same time prevent severe stigmatization of both patients and their families."

The Table 1 enlists the institutions, organizations and associations that have joined the statement of the WADD, WPA (Section on Dual Disorders), and SEPD.

\section{Acknowledgments}

WADD, WPA (Section on Dual Disorders), and SEPD thank the editors and editorial board of the international scientific journal Salud Mental for the opportunity to publish in six languages ( $E n$ glish, Spanish, Italian, French, Portuguese and German) this joint statement of international organizations with the goal of dissemi- nating the comprehension of the Dual Disorders through a scientific publication.

\section{REFERENCES}

American Psychiatric Association. (2013). Diagnostic and Statistical Manual of Mental Disorders (DSM-5). Arlington, VA: American Psychiatric Association. doi: 10.1176/appi.books.9780890425596.744053

Arias, F., Szerman, N., Vega, P., Mesias, B., Basurte, I., Morant, C., ... \& Babín, F. (2013). Madrid study on the prevalence and characteristics of outpatients with dual pathology in community mental health and substance misuse services. Adicciones, 25(2), 118-27. doi: 10.1080/17523281.2012.748674

Greenfield, S. F., \& Weiss, R. D. (2015). Harvard Review of Psychiatry: Introduction. Harvard Review of Psychiatry, 23(2), 61-62. doi: 10.1097/ HRP.0000000000000074

Kessler, R. C., Hwang, I., LaBrie, R., Petukhova, M., Sampson, N., Winters, K. C., \& Shaffer, H. J. (2008). DSM-IV pathological gambling in the National Comorbidity Survey Replication. Psychological Medicine, 38(9), 1351-1360. doi: 10.1017/S0033291708002900

Lev-Ran, S., Imtiaz, S., Rehm, J., \& Le Foll, B. (2013). Exploring the association between lifetime prevalence of mental illness and transition from substance use to substance use disorders: Results from the National Epidemiologic Survey of Alcohol and Related Conditions (NESARC). American Journal on Addictions, 22(2), 93-98. doi:10.1111/j.1521-0391.2013.00304.x

Leyton, M., \& Vezina, P. (2014). Dopamine ups and downs in vulnerability to addictions: A neurodevelopmental model. Trends in Pharmacological Sciences. doi: 10.1016/j.tips.2014.04.002

Mann, K., Roos, C., Hoffmann, S., Nakovics, H., Leméganer, T., Heinz, A., \& Wictiewitz, K. (2017). Precision medicine in alcohol dependence: A controlled trial testing pharmacotherapy response among reward an relief dinking phenotype. Neuropsychopharmacology. Retrieved from: https://www.nature.com/articles/ npp2017282

Minkoff, K. (2001). Best Practices: Developing Standards of Care for Individuals With Co-occurring Psychiatric and Substance Use Disorders. Psychiatric Services, 52(5), 597-599. doi: 10.1176/appi.ps.52.5.597

National Institute on Drug Abuse. (2007). Addiction and co-occurring mental disorders.

Roncero, C., Barral, C., Rodríguez-Cintas, L., Pérez-Pazos, J., Martinez-Luna, N., Casas, M., ... \& Grau-López, L. (2016). Psychiatric comorbidities in opioid-dependent patients undergoing a replacement therapy programme in Spain: The PROTEUS study. Psychiatry Research, 243, 174-181. doi: 10.1016/j.psychres.2016.06.024

Szerman, N., \& Martinez-Raga, J. (2015). Editorial. Advances in Dual Diagnosis, 8(2). doi: 10.1108/ADD-03-2015-0004

Szerman, N., Martinez-raga, J., Peris, L., Roncero, C., Basurte, I., Vega, P., ... \& Casas, M. (2013). Rethinking Dual Disorders/Pathology. Addictive Disorders \& Their Treatment, 12(1). doi: 10.1097/ADT.0b013e31826e7b6a

Van Os, J., Delespaul, P., Wigman, J., Myin-Germeys, I., \& Wichers, M. (2013). Beyond DSM and ICD: Introducing "precision diagnosis" for psychiatry using momentary assessment technology. World Psychiatry, 12(2), 113-117. doi: $10.1002 / w p s .20046$

Volkow, N. D. (2001). Drug abuse and mental illness: Progress in understanding comorbidity. American Journal of Psychiatry, 158(8), 1181-1183. doi: 10.1176/ appi.ajp.158.8.1181

Volkow, N. D., Koob, G. F., \& McLellan, A. T. (2016). Neurobiologic Advances from the Brain Disease Model of Addiction. The New England Journal of Medicine, 374(4), 363-371. doi: 10.1056/NEJMra1511480 